\title{
Optimal fiscal stabilization policy with credible central bank independence
}

\author{
Luca Lambertini - Riccardo Rovelli \\ Department of Economics, University of Bologna \\ Strada Maggiore 45, 40125 Bologna, Italy \\ lamberti@spbo.unibo.it; rovelli@spbo.unibo.it \\ phone: +39-051-2092600; fax: +39-051-2092664
}

December 21, 2002

\begin{abstract}
We study a model where monetary and fiscal policy share the task of stabilizing output and inflation, and the central bank has been assigned a mandate for the latter. The optimal fiscal policy does not imply assigning to the government a (symmetric) mandate to stabilize output. Instead, the optimal response to aggregate demand and supply shocks may be characterized as equivalent to an automatic stabilizer.

An alternative but equivalent characterization of fiscal policy is that the government should maximize a "modified" social welfare function, respectively over (under) weighting the objective of price stability versus output stability when the relative size of aggregate demand vs. supply shocks is large (small). This over (under) weighting of the two objectives is only apparent, as it is in fact the logical consequence of having defined the mandate of the central bank in terms of one objective only.

Keywords: Stabilization policy, Monetary policy, Fiscal policy, Policy coordination.

JEL codes: E610, E630.
\end{abstract}




\section{Introduction}

In recent models of monetary policy, the primary goal assigned to policy is price or inflation stabilization, with stabilization of aggregate demand shocks relevant only as a subordinate or intermediate goal. At the same time, it is widely accepted that "in an economy in which fluctuations are partly due to the combination of aggregate demand effects and nominal rigidities, fiscal policy also [in addition to monetary policy] has the potential to reduce fluctuations in aggregate demand" (Blanchard and Fischer, 1989, p. 583). Potentially, then, situations may arise when the policy decisions of monetary and fiscal authorities will either result in a duplication of efforts or, when they are setting their instruments in opposite directions, negative externalities. Although these inefficiencies would obviously call for some form of policy coordination, this issue has traditionaly been neglected in the academic literature ${ }^{1}$. One explanation for this neglect is that, following: Barro and Gordon (1983), normative models of monetary policy have focused on risks inherent to the stabilization of supply, rather than demand shocks: see e.g. Rogoff (1985), Cukierman (1992) and Walsh (1995 and 1998, ch. 8). A different explanation is that, if fiscal policy operates through automatic stabilizers, this takes care $e x$ ante of how to coordinate policy actions aimed at the stabilization of aggregate demand ${ }^{2}$.

More recently, the theory of monetary policy has explicitly taken into account "frictions such as nominal price rigidities" (Clarida, Gali and Gertler, 1999, p.1662). These rigidities imply that transmission of policy impulses take place through their impact on aggregate demand. This implication is strongly supported also by VAR models of the transmission mechanism (Christiano, Eichenbaum and Evans, 1999). Following in the spirit of this "New Keynesian" approach to monetary policy analysis, we suggest that, if both policies react to the same set of macroeconomic shocks, then this should naturally lead us to model explicitly the coordination between fiscal

\footnotetext{
${ }^{1}$ See for instance Chari and Kehoe (1999). Issues of coordination between fiscal and monetary policies do however appear in some areas of macroeconomics, e.g. in models of the optimal inflation tax or seigniorage policy (Barro, 1979; Lucas and Stokey, 1983) and in models of the long-run dynamics of government debt (Sargent and Wallace, 1981 and, in the framework of the fiscal theory of the price level, Leeper, 1991 and Woodford, 1995).

${ }^{2}$ Analyses of the effectiveness of automatic fiscal stabilizers do not generally take monetary policy into account. See e.g. Auerbach e Feenberg (2000) for the US and Brunila, Buti and in 'tVeld (2002) for the euro area.
} 
and monetary policies. So far, this issue has not been explicitly addressed in theory, except in the context of models of the Economic and Monetary Union (EMU) in Europe ${ }^{3}$. Regarding EMU, also the policy debate on these issues is quite active, especially in reference to the role of the Stability and Growth Pact ${ }^{4}$. Although these debates have been heavily influenced by the coexistence, in EMU, of decentralized (national) fiscal authorities together with a centralized monetary authority (the European Central Bank), we argue below that the theoretical arguments underlying this debate arise also in the context of a single country model, whenever monetary policy is delegated to an authority which enjoys some degree of independence.

In this paper, we model the interaction of monetary and fiscal policy as tools of macroeconomic stabilization, in the context of a well known model of aggregate demand and supply. Although there are two policy objectives, inflation and output stabilization, they are not independent of each other, since temporary output deviations also cause price deviations. Moreover, there are two policy instruments (the government budget and the nominal interest rate) which both directly affect aggregate demand. In this context, we assume that monetary policy (that is, the setting of nominal interest rates for the purpose of price stabilization) has been assigned to an instrumentindependent ${ }^{5}$ agent (the central bank), presumably to avoid issues of time-

\footnotetext{
${ }^{3}$ See several of the papers collected in Beetsma et al. (2003). We analyze formally the strategic interaction between monetary and fiscal authorities in the context of EMU in Lambertini and Rovelli (2002; 2003).

${ }^{4}$ The importance of policy coordination for a successful macroeconomic stabilization has been expplicitly acknowledged by both fiscal and monetary policy authorities in the EMU. The following quotation from the Broad Economic Policy Guidelines of the European Commission (March 2001) is a fitting example:"Budgetary policies should continue to be geared to the achievement of public finances close to balance or in surplus, so as to support the price-stability orientation of monetary policy, and thereby to foster continued economic growth and employment creation". And for the ECB: "The expansionary fiscal policies planned for this year [2001] in a number of euro area countries are not conducive to containing aggregate demand and inflationary pressures. Particularly in the countries experiencing high economic growth rates, inflationary pressures will receive an additional stimulus from expansionary fiscal policies" (ECB Annual Report 2000, May 2001, p. 47).

${ }^{5}$ Instrument-independence (see Debelle and Fischer, 1994) means that the central bank has the freedom to adjust its policy instrument (the nominal interest rate) in order to best achieve the objective assigned to it (inflation stabilization). Notice that in this paper we identify central bank independency with instrument-independency, subject to a mandate for price stability. This may be appropriate for the case of EMU; for a general survey and discussion of the relation between independency and price stability, see Hayo and Hefeker
} 
inconsistency in the pursuit of its policies. Our results, to be presented in detail below, will show that, in this case, fiscal policy should optimally respond to both aggregate demand and supply shocks, and that this response can be characterized as an "automatic stabilizer", implying that no discretionary policy action needs to be taken each period. We will also explore in some detail how the mandate assigned to the fiscal policy authority should be optimally defined, when monetary policy is assigned to an independent central bank.

\section{The model}

We analyze a simple model of a closed economy, which is the static equivalent of a conventional aggregate demand/aggregate suppy model, with short run price rigidity. ${ }^{6}$ In the short run, we may observe a positive value of the output gap $\left(y>y^{*}\right)$ following either an expansionary monetary policy (which temporarily lowers the real rate of interest, $i-\pi^{*}$, below the long run equilibrium value, $\bar{r}$ ), or an expansionary fiscal policy $(f>0)$ or an unexpected positive demand shock, $\varepsilon_{1}$.

$$
\mathrm{AD}: y=y^{*}-\alpha\left(i-\pi^{*}-\bar{r}\right)+\eta f+\varepsilon_{1}
$$

To simplify notation, we may redefine: $\bar{r}+\pi^{*}=\pi^{*}$. On the supply side inflation, $\pi$, will increase/decrease relative to its expected or target level, $\pi^{*}$, in response to positive/negative values of the output gap, and also to unexpected supply shocks $\varepsilon_{2}$ :

$$
\text { AS }: \pi=\pi^{*}+\beta\left(y-y^{*}\right)+\varepsilon_{2}
$$

Also note that $\alpha, \beta, \eta$ are positive parameters and that the shocks $\varepsilon_{i}, i=$ 1,2 , are i.i.d. We shall assume that both fiscal and monetary policy can be set optimally with no lag, in response to realized values of the two shocks.

The policy problem is characterised as follows. Given the available resources, social welfare is maximum when, in the absence of shocks, $y=y^{*}$ and $\pi=\pi^{*}$. In this case it is then optimal to adopt a neutral policy stance,

$(2002)$

${ }^{6}$ See e.g. Svensson (1997), who also shows that in this class of models optimal monetary policy can be characterized as setting the nominal interest in response to aggregate demand and supply shocks. 
that is $i=\pi^{*}$ and $f=0^{7}$. When shocks occur, then the economy is temporarily driven away from the social optimum, and both fiscal and monetary policy may adopt a non-neutral stance. However, we also assume that stabilisation policies are costly, so that there are convex costs associated to the use of either policy instrument ${ }^{8}$. In this context, a natural measure of social welfare (or loss) is:

$$
\begin{gathered}
L_{S} \equiv\left(y-y^{*}\right)^{2}+\left(\pi-\pi^{*}\right)^{2}+\gamma f^{2}+\mu\left(i-\pi^{*}\right)^{2} \\
=\left[\eta f-\alpha\left(i-\pi^{*}\right)+\varepsilon_{1}\right]^{2}+\left[\beta\left(\eta f-\alpha\left(i-\pi^{*}\right)+\varepsilon_{1}\right)+\varepsilon_{2}\right]^{2}+\gamma f^{2}+\mu\left(i-\pi^{*}\right)^{2}
\end{gathered}
$$

where subscript $S$ stands for social. We assume that the government has assigned to the central bank the exclusive task of pursuing price stability, which, taking into account the cost of using the associated policy instrument, is operationally defined by the following objective:

$$
\min _{i} L_{B}=\left[\beta\left(\eta f-\alpha\left(i-\pi^{*}\right)+\varepsilon_{1}\right)+\varepsilon_{2}\right]^{2}+\mu\left(i-\pi^{*}\right)^{2}
$$

where subscript $B$ stands for bank. The government will then leave for itself the task of setting fiscal policy $f$, taking into account that the goal of price stabilization has been delegated to the central bank. Hence, the government objective will be defined operationally as:

$$
\min _{f} L_{G}=\left[\eta f-\alpha\left(i-\pi^{*}\right)+\varepsilon_{1}\right]^{2}+\gamma f^{2}+\theta L_{B}
$$

where subscript $G$ stands for government and the weight $\theta$ will be chosen endogenously, and may in general be different from 1 . It is now convenient to define also:

$$
L_{T}=\left[\eta f-\alpha\left(i-\pi^{*}\right)+\varepsilon_{1}\right]^{2}+\gamma f^{2}
$$

\footnotetext{
${ }^{7}$ This is compatible with the optimal setting of tax rates/subisidies, so that in fact the equilibrium level of output coincides with its potential or natural level, $y^{*}$, in the absence of any shock.

${ }^{8}$ The cost of manoeuvring fiscal policy away from the assigned long run level (which is assumed here for simplicity to be a balanced budget, i.e. $f=0$ ) may be interpreted as originating either from long run considerations (the desire to avoid debt accumulation of decumulation) or from considerations relative to the optimal level of private vs. public expenditures. The cost of changing the nominal interest rate may also originate from crowding out considerations, or from the desire to smooth the volatility of interest rates (possibly to avoid monetary or financial instability). See Walsh (1998, ch.10).
} 
where $T$ stands for treasury. This allows us to write the loss functions more compactly as:

$$
L_{G}=L_{T}+\theta L_{B} ; L_{S}=L_{T}+L_{B}
$$

Now consider the simultaneous game between the central bank and the government. For any given $\theta$, first order conditions are:

$$
\begin{gathered}
\frac{\partial L_{B}}{\partial i}=2 \mu\left(i-\pi^{*}\right)-2 \alpha \beta\left[\beta\left(\eta f-\alpha\left(i-\pi^{*}\right)+\varepsilon_{1}\right)+\varepsilon_{2}\right]=0 \\
\frac{\partial L_{G}}{\partial f}=2 \gamma f+2 \eta\left(1+\beta^{2} \theta\right)\left(\eta f-\alpha\left(i-\pi^{*}\right)+\varepsilon_{1}\right)+2 \beta \eta \theta \varepsilon_{2}=0
\end{gathered}
$$

yielding:

$$
\begin{aligned}
f^{N} & =\frac{\eta\left[\beta\left(\alpha^{2}-\mu \theta\right) \varepsilon_{2}-\mu \varepsilon_{1}\left(1+\beta^{2} \theta\right)\right]}{\gamma\left(\alpha^{2} \beta^{2}+\mu\right)+\eta^{2} \mu\left(1+\beta^{2} \theta\right)} \\
i^{N} & =\pi^{*}+\frac{\alpha \beta\left[\varepsilon_{2}\left(\eta^{2}+\gamma\right)+\beta \gamma \varepsilon_{1}\right]}{\gamma\left(\alpha^{2} \beta^{2}+\mu\right)+\eta^{2} \mu\left(1+\beta^{2} \theta\right)}
\end{aligned}
$$

where superscript $N$ stands for Nash equilibrium. Two observations are appropriate at this point. First, notice that, for any given level of $\pi^{*}$, there exist extreme configurations of demand and supply shocks under which the optimal interest rate would be negative, implying that either the central bank should revise upward the inflation target, or fiscal policy should, ceteris paribus, become more expansive. Second, for future reference notice that

$$
\frac{\partial i^{N}}{\partial \varepsilon_{k}}>0 ; \frac{\partial^{2} i^{N}}{\partial \varepsilon_{k} \partial \theta}<0, k=1,2,
$$

and also:

$$
\frac{\partial f^{N}}{\partial \varepsilon_{1}}<0 ; \frac{\partial^{2} f^{N}}{\partial \varepsilon_{1} \partial \theta}<0
$$

implying that the optimal fiscal policy response to aggregate demand shocks is always negative, and increases in absolute value with $\theta$.

The equilibrium losses associated with the Nash equilibrium are:

$$
L_{B}^{N}=\frac{\mu\left(\alpha^{2} \beta^{2}+\mu\right)\left[\beta \gamma \varepsilon_{1}+\left(\eta^{2}+\gamma\right) \varepsilon_{2}\right]^{2}}{\left[\gamma\left(\alpha^{2} \beta^{2}+\mu\right)+\eta^{2} \mu\left(1+\beta^{2} \theta\right)\right]^{2}}
$$




$$
\begin{gathered}
L_{T}^{N}=\frac{\gamma\left(\eta^{2}+\gamma\right)\left(\alpha^{2} \beta \varepsilon_{2}-\mu \varepsilon_{1}\right)^{2}-\beta^{2} \eta^{2} \mu \Omega}{\left[\gamma\left(\alpha^{2} \beta^{2}+\mu\right)+\eta^{2} \mu\left(1+\beta^{2} \theta\right)\right]^{2}} \\
\Omega \equiv 2 \varepsilon_{1} \gamma \theta\left(\alpha^{2} \beta \varepsilon_{2}-\mu \varepsilon_{1}\right)-\mu \theta^{2}\left(\eta^{2} \varepsilon_{2}^{2}+\gamma\left(\beta \varepsilon_{1}+e_{2}\right)^{2}\right) \\
L_{G}^{N}=L_{T}^{N}+\theta L_{B}^{N} ; L_{S}^{N}=L_{T}^{N}+L_{B}^{N} .
\end{gathered}
$$

First of all, from (13) one immediately obtains $\partial L_{B}^{N} / \partial \theta<0$ always, which implies the following intuitive property:

Lemma 1 The central banker's task becomes progressively easier as the weight attached by the government to price stability increases.

This is also consistent with the observation that the central bank's reaction to either shock is less pronounced as $\theta$ increases, as can be seen from (11).

Now we can differentiate the social welfare $\operatorname{loss} L_{S}^{N}$ w.r.t. the weight $\theta$ :

$$
\frac{\partial L_{S}^{N}}{\partial \theta}=\frac{2 \beta^{2} \eta^{2} \mu\left[\beta \gamma \varepsilon_{1}+\varepsilon_{2}\left(\gamma+\eta^{2}\right)\right]\left[\mu^{2}(\theta-1)\left(\beta \gamma \varepsilon_{1}+\varepsilon_{2}\left(\gamma+\eta^{2}\right)\right)+\Psi\right]}{\left[\alpha^{2} \beta^{2} \gamma+\mu\left(\gamma+\eta^{2}\left(1+\beta^{2} \theta\right)\right)\right]^{3}}=0
$$

where

$$
\Psi \equiv \alpha^{2} \beta\left[\mu\left(\gamma \varepsilon_{1}\left(1+\beta^{2}(\theta-1)\right)-\beta \varepsilon_{2}\left(\eta^{2}+\gamma(1-\theta)\right)\right)-\alpha^{2} \beta \gamma \varepsilon_{2}\right]
$$

Solving (16) w.r.t. $\theta$ yields:

$\theta_{G}=\frac{\alpha^{4} \beta^{2} \gamma \varepsilon_{2}+\mu\left[\alpha^{2} \beta\left(\beta \varepsilon_{2}\left(\eta^{2}+\gamma\right)-\gamma \varepsilon_{1}\left(1-\beta^{2}\right)\right)+\mu\left(\beta \gamma \varepsilon_{1}+\varepsilon_{2}\left(\eta^{2}+\gamma\right)\right)\right]}{\mu\left[\alpha^{2} \beta^{2} \gamma\left(\beta \varepsilon_{1}+\varepsilon_{2}\right)+\mu\left(\beta \gamma \varepsilon_{1}+\varepsilon_{2}\left(\eta^{2}+\gamma\right)\right)\right]}$

If $\varepsilon_{1}=0, \varepsilon_{2} \neq 0$ :

$$
\theta_{G}=\frac{\alpha^{4} \beta^{2} \gamma+\mu\left(\eta^{2}+\gamma\right)\left(\alpha^{2} \beta^{2}+\mu\right)}{\alpha^{2} \beta^{2} \gamma+\mu\left(\eta^{2}+\gamma\right)}>0
$$

If $\varepsilon_{1} \neq 0, \varepsilon_{2}=0$ :

$$
\theta_{G}=\frac{\alpha^{2}(\beta+1)(\beta-1)+\mu}{\alpha^{2} \beta^{2}+\mu}
$$

whose sign depends upon the size of $\beta$. In fact, if $\beta$ is very small, $\theta_{G}$ may become negative, implying that the government can stabilise demand shocks 
without taking notice of their inflationary impact. Nevertheless, as implied by (12), fiscal policy will never be set so as to destabilise the demand side.

If $\varepsilon_{1}=\varepsilon_{2}=0$, then $\theta_{G}$ is obviously indeterminate since no policy action needs to take place. It is easy to check that, in this case, $f^{N}=0$ and $i^{N}=\pi^{*}$.

Now we examine the case where both shocks differ from zero. Observe that the numerator of $\theta_{G}$ is nil at:

$$
\varepsilon_{2 a}=-\frac{\beta \gamma \mu \varepsilon_{1}\left[\alpha^{2}(\beta+1)(\beta-1)+\mu\right]}{\alpha^{2} \beta^{2}\left[\alpha^{2} \gamma+\mu\left(\eta^{2}+\gamma\right)\right]+\mu^{2}\left(\eta^{2}+\gamma\right)}
$$

Next, the denominator of $\theta_{G}$ is nil at:

$$
\varepsilon_{2 b}=-\frac{\beta \gamma \varepsilon_{1}\left(\alpha^{2} \beta^{2}+\mu\right)}{\alpha^{2} \beta^{2} \gamma+\mu\left(\eta^{2}+\gamma\right)}
$$

Moreover, we are also interested in determining the shock ranges wherein the optimal weight $\theta_{G}$ is larger than one. This would be a case where fiscal policy would concentrate more on aggregate supply rather than demand shocks. Presumably, this would be the case when the economy is characterised by very high price instability (i.e., very large supply shocks). To prove this point, define $\hat{\theta} \equiv \theta_{G}-1$. Then we have that the numerator of $\hat{\theta}$ is equal to zero at:

$$
\varepsilon_{2 c}=\frac{\gamma \mu \varepsilon_{1}}{\beta\left(\alpha^{2} \gamma+\eta^{2} \mu\right)}
$$

while the denominator of $\hat{\theta}$ is zero at:

$$
\varepsilon_{2 d}=-\frac{\beta \gamma \varepsilon_{1}\left(\alpha^{2} \beta^{2}+\mu\right)}{\alpha^{2} \beta^{2} \gamma+\mu\left(\eta^{2}+\gamma\right)}=\varepsilon_{2 b}
$$

Now some tedious algebra suffices to verify that, for all $\varepsilon_{1}>0$ :

$$
\varepsilon_{2 b}=\varepsilon_{2 d}<\varepsilon_{2 a}<\varepsilon_{2 c}
$$

with $\varepsilon_{2 b}=\varepsilon_{2 d}<0$ and $\varepsilon_{2 c}>0$ surely, while the sign of $\varepsilon_{2 a}$ depends upon the size of $\beta$. If instead $\varepsilon_{1}<0$ :

$$
\varepsilon_{2 c}<\varepsilon_{2 a}<\varepsilon_{2 b}=\varepsilon_{2 d}
$$

with $\varepsilon_{2 b}=\varepsilon_{2 d}>0$ and $\varepsilon_{2 c}<0$ surely, while the sign of $\varepsilon_{2 a}$ again depends upon the size of $\beta$.

We are now able to establish the following: 
- $\varepsilon_{1}>0$. In this case, (i) $\theta_{G}>1$ if either $\varepsilon_{2}<\varepsilon_{2 b}=\varepsilon_{2 d}$ or $\varepsilon_{2}>\varepsilon_{2 c}$; (ii) $\theta_{G}<0$ for all $\varepsilon_{2} \in\left(\varepsilon_{2 b}=\varepsilon_{2 d}, \varepsilon_{2 a}\right)$; (iii) $\theta_{G} \in(0,1)$ for all $\varepsilon_{2} \in\left(\varepsilon_{2 a}, \varepsilon_{2 c}\right)$.

- $\varepsilon_{1}<0$. In this case, $\theta_{G}>1$ if either $\varepsilon_{2}<\varepsilon_{2 c}$ or $\varepsilon_{2}>\varepsilon_{2 b}=\varepsilon_{2 d}$; (ii) $\theta_{G} \in(0,1)$ for all $\varepsilon_{2} \in\left(\varepsilon_{2 c}, \varepsilon_{2 a}\right)$; (iii) $\theta_{G}<0$ for all $\varepsilon_{2} \in\left(\varepsilon_{2 a}, \varepsilon_{2 b}=\varepsilon_{2 d}\right)$.

In particular, the above results imply the following:

$$
\begin{aligned}
& \theta_{G}>1 \text { for all }\left|\frac{\varepsilon_{2}}{\varepsilon_{1}}\right|>\max \left\{\left|\frac{\varepsilon_{2 b}}{\varepsilon_{1}}=\frac{\varepsilon_{2 d}}{\varepsilon_{1}}\right|,\left|\frac{\varepsilon_{2 c}}{\varepsilon_{1}}\right|\right\} \\
& \theta_{G}<0 \text { for all }\left|\frac{\varepsilon_{2}}{\varepsilon_{1}}\right| \in\left(\min \left\{\left|\frac{\varepsilon_{2 a}}{\varepsilon_{1}}\right|,\left|\frac{\varepsilon_{2 b}}{\varepsilon_{1}}=\frac{\varepsilon_{2 d}}{\varepsilon_{1}}\right|\right\}, \max \left\{\left|\frac{\varepsilon_{2 a}}{\varepsilon_{1}}\right|,\left|\frac{\varepsilon_{2 b}}{\varepsilon_{1}}=\frac{\varepsilon_{2 d}}{\varepsilon_{1}}\right|\right\}\right)
\end{aligned}
$$

On the basis of (27), we are entitled to state:

Proposition 2 If the central bank has been given a mandate for price stability, the optimal fiscal policy set by the government should overweigh (relative to the social loss function) the objective of price stability when demand shocks are very large relative to supply shocks. It should instead give a negative weight to price stability when supply shocks are sufficiently small relative to demand shocks.

To understand the implications of this Proposition, we may see what it implies for the choice of the optimal fiscal policy. Plugging (18) into (10), we can rewrite the optimal fiscal stance as follows:

$$
f^{N}=-\frac{\eta \mu\left[\left(\alpha^{2} \beta^{4}+\left(1+\beta^{2}\right) \mu\right) \varepsilon_{1}+\beta\left(\mu-\alpha^{2}(1-\beta)(1+\beta)\right) \varepsilon_{2}\right]}{\alpha^{2} \beta^{2}\left(\alpha^{2} \beta^{2} \gamma+\left(2 \gamma+\beta^{2} \eta^{2}\right) \mu\right)+\left(\gamma+\eta^{2}\left(1+\beta^{2}\right)\right) \mu^{2}}
$$

or equivalently:

$$
f^{N}=-\Gamma\left(\Phi \varepsilon_{1}+\Lambda \varepsilon_{2}\right)
$$

with

$$
\begin{aligned}
\Gamma & \equiv \frac{\eta \mu}{\alpha^{2} \beta^{2}\left(\alpha^{2} \beta^{2} \gamma+\left(2 \gamma+\beta^{2} \eta^{2}\right) \mu\right)+\left(\gamma+\eta^{2}\left(1+\beta^{2}\right)\right) \mu^{2}}>0 \text { always; } \\
\Phi & \equiv \alpha^{2} \beta^{4}+\left(1+\beta^{2}\right) \mu>0 \text { always; } \\
\Lambda & \equiv \beta\left(\mu-\alpha^{2}(1-\beta)(1+\beta)\right)>0 \text { iff } \mu-\alpha^{2}(1-\beta)(1+\beta)>0
\end{aligned}
$$

Hence we are entitled to state the following : 
Corollary 3 Given that the central bank has been assigned a credible mandate for price stability, the optimal fiscal stabilization policy: (i) cannot in general be characterized by assigning to fiscal policy a "simple" mandate to stabilize either the output gap or a linear function of the output gap and inflation deviations; (ii) can be characterized in term of a fixed linear response to aggregate demand and supply shocks.

Notice that, since the general format of eq.(28) can be compactly written as $f^{N}=-\Gamma\left(\Phi \varepsilon_{1}+\Lambda \varepsilon_{2}\right)$, this optimal rule is qualitatively compatible with the specification of automatic fiscal stabilizers ${ }^{9}$. We may also notice that the optimal response of fiscal policy to an aggregate demand shock is always negative (that is, $f$ increases when there is a negative shock), whereas the optimal response to an aggregate supply shock is more likely to also be negative when $\beta$ is "large"10, that is when the impact of aggregate demand on inflation is large.

\section{Concluding remarks}

In this note we have shown that, if both monetary policy (i.e., the setting of nominal interest rates by the central bank) and fiscal policy (the setting of the fiscal stance by the government) affect the level of aggregate demand (at least temporarily, in the case of monetary policy, due to the presence of short-run price rigidities) then an issue of policy coordination arises. We have examined this issue for the case when monetary and fiscal policies are simultaneously set by two different agents.

Our results show that, if a mandate for price stability has been assigned to the central bank, then the optimal fiscal policy cannot be characterized by assigning to the government a (symmetric) mandate to stabilize output against demand shocks. More generally, the optimal fiscal policy cannot be characterized in terms of a mandate to minimize a linear function of

\footnotetext{
${ }^{9}$ For instance, if tax revenues respond to shocks to aggregate demand and unemployment susbisidies are a function of shocks to aggregate supply, then the behavior of the budget over the business cycle could be described by an equation qualitatively identical to our eq.(28). For a more practical example, see Cohen and Follet (2000, p.42), who explictly simulate the reaction of automatic stabilizers in the FRS/US quarterly model to both shocks to aggregate demand and supply.

${ }^{10}>$ From equation (28), we see that as $\beta \rightarrow 0$, the response of fiscal policy to an aggregate supply shock is negative only if $\mu>\alpha^{2}$.
} 
deviations from the output and inflation targets. We have shown that this has at least two implications.

First, fiscal stabilization policy will optimally respond to both aggregate demand and supply shocks. This response can in general be characterized as an "automatic stabilizer", implying that no discretionary policy action needs to be taken each period. This has the following additional desirable implication, which becomes relevant in a setting of decentralized national fiscal policies within a monetary union (such as in EMU): if national automatic stabilizers are optimally designed, this (provided there are no fiscal policy spillovers across countries) will provide also the desirable degree of coordination between national fiscal policies, and no further discretionary action is required either at the national or at the aggregate level.

Second, as we state in Proposition 2, the optimal fiscal policy may be interpreted as if the government were maximizing a "modified" social welfare function, respectively over/under weighting the objective of price stability versus output stability when the relative size of aggregate demand vs. supply shocks is "large" or "small". We have shown that this over or under weighting of the two objectives is the logical consequence of having defined the mandate of the central bank only in terms of price stability.

A natural extension of this analysis would be to consider non-simultaneous moves by the two agents. We study extensively this case in Lambertini and Rovelli (2002)

\section{References}

[1] Auerbach, A.J. and D. Feenberg(2000), "The Significance of Federal Taxes as Automatic Stabilizers", Journal of Economic Perspectives, 14, Summer, pp.37-56.

[2] Barro, R.J. (1979) "On the Determination of Public Debt", Journal of Political Economy, 87, pp.940-971.

[3] Barro, R.J. and D. Gordon (1983) "Rules, Discretion and Reputation in a Model of Monetary Policy", Journal of Monetary Economics, 12, pp.101-122.

[4] Beetsma, R.,C. Favero, A. Missale, V.A. Muscatelli, P. Natale and P. Tirelli (eds.)(2003) "Fiscal Policies, Monetary Policies and Labour Mar- 
kets. Key Aspects of European Macroeconomic Policies after Monetary Unification", Cambridge U.P.(Forthcoming).

[5] Blanchard, O.J. and S. Fischer (1989) "Lectures on Macroeconomics", Cambridge, Ma, MTT Press.

[6] Brunila, A., M. Buti and J. in 'tVeld (2002) "Fiscal policy in Europe: how effective are automatic stabilisers?" European Commission - DG for Economic and Financial Affairs Economic Papers, no. 177, September.

[7] Chari, V.V. and P.J. Kehoe (1999), "Optimal Fiscal and Monetary Policy", Handbook of Macroeconomics, North Holland, Vol.1c, Ch.26.

[8] Christiano, L.J., M. Eichenbaum and C.L. Evans (1999) "Monetary Policy Shocks: What Have we Learned and to What End?", Handbook of Macroeconomics, North Holland, Vol.1a, Ch.2.

[9] Cohen D. and G. Follet (2000), "The Automatic Fiscal Stabilizers: Quietly Doing Their Thing", Federal Reserve Bank of New York Policy Review, April, pp.35-68.

[10] Cukierman, A. (1992) "Central Bank Strategy, Credibility and Independence", Cambridge, Ma, MTT Press.

[11] Debelle, G. and S. Fischer (1994) "How Independent Should a Central Bank Be?" In J.C. Fuhrer (ed.), Goals, Guidelines, and Constraints Facing Monetary Policymakers, Federal Reserve Bank of Boston, Conference Series No.38, 195-221.

[12] Hayo, B. and C. Hefeker (2002) "Reconsidering Central Bank Independence", European Journal of Political Economy, 18, pp.653-674.

[13] Lambertini, L. and R. Rovelli (2002), "Monetary and fiscal policy coordination and macroeconomic stabilization. A theoretical analysis", working paper (August).

[14] Lambertini, L. and R. Rovelli (2003), "Independent or Coordinated? Monetary and Fiscal Policy in EMU", in Beetsma et al. (eds), Fiscal Policies, Monetary Policies and Labour Markets: Key Aspects of European Macroeconomic Policies after Monetary Unification, Cambridge University Press, forthcoming. 
[15] Leeper, E.M. (1991) "Equilibria Under Active and Passive Monetary and Fiscal Policy", Journal of Monetary Economics, 27, 129-147.

[16] Lucas, R.E. and N.L.Stokey (1983) "Optimal Fiscal and Monetary Policy in and Economy without Capital", Journal of Monetary Economics, 12, pp.55-94.

[17] Sargent, T.J. and Wallace, N. (1981), "Some Unpleasant Monetarist Arithmetic", FRB of Minneapolis Quarterly Review, 5, no.3, 1-17.

[18] Svensson L. (1997), "Inflation Forecast Targeting: Implementing and Monitoring Inflation Targets", European Economic Review, 41, 11111146.

[19] Walsh, C.E. (1998), Monetary Theory and Policy, Cambridge, MA, MIT Press.

[20] Woodford, M. (1995) "Price Level Determinacy Without Control of a Monetary Aggregate", Carnegie-Rochester Conference Series on Public Policy, 43, 1-46. 